\title{
La Argentina de fiesta. El discurso literario frente al Centenario. Un punto de fuga
}

Claudio Maíz

\section{Ritos y símbolos del fasto}

La joven imagen masculina, desnuda y parada sobre una roca, casi como una esfingie, con un viento soplando desde la espalda que arremolina sus cabellos, sostiene en sus dos manos el escudo argentino extendido hacia delante. Al fondo, un conjunto de nubes sugiere la idea de la altura a la que ha ascendido. Se trata de la portada a color que ilustra un volumen de más de 300 páginas con el que el diario La Nación aportó a la conmemoración del Centenario de la Revolución de Mayo. La edición ha dejado quizá el más acabado epítome del festejo. En sus páginas conviven pacíficamente textos de Rubén Darío, Leopoldo Lugones, Ricardo Rojas, Joaquín V. González, Agustín Alvarez y otros intelectuales y escritores prominentes junto a las reseñas generales sobre los ferrocarriles, la ganadería, la agricultura, las compañías y sociedades anónimas. Difícilmente pueda encontrarse en la historia cultural argentina una circunstancia parecida.

La celebración centenarista forma parte de una política de la memoria, puesto que el estado oligárquico promovió, con todos los medios a su alcance, los fastos del evento. La celebración no destacaba los diversos sentidos con los que se concebía la nacionalidad, únicamente, 
sino la complacencia de una clase social, con la que la nacionalidad se identificaba. Estas políticas de la memoria tienen que ver con las diversas formas de reminiscencia, como Todorov las ha distinguido: el pasado puede ser leído de manera literal o de manera ejemplar ${ }^{1}$. La oligarquía argentina consideró el episodio pasado de modo ejemplar, es decir, extrajo de él las confirmaciones del presente, que corroboraban el éxito económico obtenido. Por otro lado, el culto a la memoria, tan especialmente dirigido hacia un acontecimiento, combina la necesidad de una identidad colectiva con la destrucción de identidades tradicionales, como consecuencia, entre otras razones, del impacto inmigratorio ${ }^{2}$. A la luz de estos significativos acontecimientos se galvaniza un determinado nacionalismo argentino, que sienta sus raíces en el temor a lo extranjero.

Los festejos del centenario significan un aprovechamiento político de un acontecimiento histórico. Hay una ritualización de los festejos que ha despojado al hecho mismo de la Revolución de Mayo de toda significación heroica y lo resignifica en favor de intereses determinados y del poder del estado controlado por la clase terrateniente. Es preciso distinguir, entonces, entre la funcionalización política de la tradición del uso cultural que de la misma se hace, lo cual no implica que no coincidan, por ejemplo, en determinados textos literarios. Ciertos discursos literarios a los que aludiremos no impugnan ni rechazan la estructura que da origen a los festejos en los términos expresados, sino que por el contrario se suman a ellos mediante la consolidación de la imagen fecunda, apacible, presuntuosa de la Argentina. En otros términos, tales discursos contribuyen a tornar natural una determinada tradición, a tal punto que se la experimenta como verdaderamente acontecida y no como una construcción simbólica ${ }^{3}$. La formación discursiva del centenario se estructura de tal manera que no admite el disenso en la presentación de la imagen intachable de la Argentina. Es preciso analizar las causas que contribuyen a desalentar las miradas críticas.

La oligarquía argentina vive su momento de mayor esplendor, y ha convertido en sentido común lo que no es más que sentido de clase. En rigor, se trata de una coincidencia entre distintos sectores de la sociedad argentina que han obtenido beneficios derivados del nuevo orden colonial ${ }^{4}$. Aunque la distribución es extremadamente desigual, la presión de los sectores medios se hace relativamente de manera pacífica, como la abstención sostenida por Yrigoyen. Distinto es el caso de México, donde 
hacia 1910 estalla una revolución que pone, entre otros conflictos, en un primer plano el problema de la tierra y su injusta repartición, una circunstancia que no era significativa mente distinta en la Argentina. En líneas generales, la coincidencia aludida contribuía a crear la idea de que la Argentina había encontrado su camino, pero se trata en realidad de la culminación de un ciclo iniciado con la generación del $80^{5}$.

Nuestro principal propósito consiste en examinar, entonces, este complejo momento. a través del discurso literario. No es difícil advertir una notable correspondencia entre la formación discursiva hegemónica, manifestada en una confianza ilimitada en el futuro, y las condiciones socio-históricas que lo permiten y alientan. El sistema de reglas que otorga unidad a un conjunto de enunciados gira en torno a una Argentina imaginada como monumental, potente, movida por impulsos propios. Esta idea de grandeza no es megalómana sino hiperbólica y debe asociarse con una verdadera concurrencia de factores diversos, entre ellos los indicadores de una pujanza económica argentina. La formación discursiva del Centenario ha sido registrada en diversos estudios con anterioridad ${ }^{6}$, sin embargo, nos parece oportuno volver sobre la misma con el fin de revisar los discursos periféricos, que polemizan y se alternan con la homogeneidad registrada en la ideología de la euforia. Rubén Darío, Leopoldo Lugones, Ricardo Rojas y Manuel Gálvez componen, con matices, las voces representativas de aquella ideología ${ }^{7}$. Habremos de referirnos a Manuel Ugarte como la voz discordante del discurso hegemónico centenarista. La enunciación contrastiva ugarteana reconoce como causa inmediata su larga estadía europea, parisina especialmente, que le posibilitó lo que llamamos un redescubrimiento de América desde Europa, así como también su largo recorrido a través del continente americano. Sostenemos que el 'locus enuntiationis' determina la mirada de conjunto del escritor argentino, circunstancia que él mismo advierte en sus memorias ${ }^{8}$, y que incide tanto a nivel temático y la elección del género discursivo como en las estrategias compositivas.

\section{El punto de fuga}

La noción de nacionalidad decimonónica que se reactualiza hacia los primeros años del siglo $X X$ resulta funcional a las relaciones económicas neocoloniales. De ahí que los discursos sobre la nacionalidad centrada sobre sí misma, del tipo de la "argentinidad", "chilenidad" o 
"peruanidad" que aparecieron por entonces hallaran rápida difusión en los aparatos culturales. Sin embargo, el carácter limitado de este tipo de discurso ya estaba insinuado en el internacionalismo cultural que José Martí alentara. Pero también, y fundamentalmente, el sentido de esta exaltación nacionalista de tipo romántica, marca las condiciones para la verificación de un punto de fuga, como lo es el discurso americanista ugarteano. Oscar Terán ha sostenido que ciertos discursos sociales no deben ser abordados solamente desde una perspectiva estructural, es preciso señalar también "los puntos de fuga, los focos de dispersión del sistema: ciertos "conceptospuente" que permitan el pasaje hacia otro tipo de estructuras discursivas, posibilitadas a su vez por las alteraciones que se producen en el nivel de las condiciones preteóricas históricomateriales"9. El corpus ensayístico de Ugarte está organizado como un macrotexto ${ }^{10}$ según una noción heterogénea, aun cuando lo haga desde una centralidad geográfica y cultural, que es el espacio latinoamericano como una unidad. Por lo mismo, el discurso americanista ugarteano instituye un verdadero punto de fuga en la formación discursiva hegemónica. En general, el discurso americanista, forjado durante el período de modernización latinoamericana, es asediado por el criollismo conservador, por un lado, y por el desarraigo cosmopolita del modernismo estético, por otro. Ambas instancias pueden ser manipuladas alternativamente por la cultural dominante, con claros objetivos políticos, como lo demuestra la cohabitación de tales extremos en las páginas del diario La Nación.

El discurso literario del Centenario debe interrogarse no sólo por lo que dice, de suyo inexcusable, sino también por lo que calla. En efecto, si la política es aquello que prescribe una medida de referencia común y hace existir una comunidad, ni la oligarquía ni su contracara, el anarquismo, reunían el requisito de referencia común, puesto que la primera gobernaba sin la idea de nación-pueblo y el segundo, predicaba su doctrina libertaria entre los artesanos extranjeros. En ambos casos, la escenografía implantada busca legitimar la situación enunciativa que los hace posible. Tal esfuerzo no logra más que agregar un marco de ficción a la política, el mismo que permite hablar de una Argentina con doble fondo 0 la coexistencia de dos entidades distintas. Se trata de una 'dispositio' contrapuntística que ordena los discursos, en especial los de temática identitaria ${ }^{11}$. La metáfora que Eduardo Mallea recoge en su ensayo hacia los años cuarenta, la de una Argentina visible y otra invi 
sible, se cumple con toda claridad en este período, además de circular también, por entonces, en los textos literarios y periodísticos ${ }^{12}$ La gran ausencia o el gran vacío lo constituye la obstinación de Hipólito Yrigoyen a no dejarse cooptar por el régimen, "falaz y descreído", como el caudillo radical lo denominaba. En otros términos, el revés de trama de la ideología de la euforia y la confianza ilimitada está en la abstención del Partido Radical. El anarquismo, en todo caso, constituyó el ala radical izada del régimen, mas no su superación. Estas precisiones tienen un carácter necesario en virtud de que ciertos tópicos articulados por el arielismo, de intensa vigencia para el Centenario, habían puesto de manifiesto cierto malestar en la cultura. El antinorteamericanismo de Rodó que tanto complació a la oligarquía argentina debe pensarse en relación con la dependencia argentina de Gran Bretaña.

\section{El americanismo durante el centenario}

Ahora bien, la formación discursiva del Centenario actualiza un "residuo rural", que a modo de tradición ha impregnado la cultura argentina. Es un elemento que homogeneiza los textos literarios escritos 'ad hoc', u otros que se producen alrededor del año 1910. Recurso que debería sorprender ante el carácter netamente cosmopolita, moderno y europeísta que la modernización literaria en la Argentina había traído. Sin embargo, no hay razón para ello. Al proceso de modernización se le acopla inevitablemente la definición de sus tradiciones ${ }^{13}$. Dentro del conjunto sistemático de enunciados, la exaltación de las bondades de la naturaleza y la utilidad de los bienes materiales resulta el tópico predilecto, como lo demuestran sobre todo las Odas seculares de Leopoldo Lugones y el Canto a la Argentina de Rubén Darío, escritos a propósito del centenario y aparecidos en la edición especial del diario La Nación. El mensaje positivo, la comparación alentadora entre el presente y el futuro, la esperanza en el porvenir de la patria, y la contemplación extasiada del espectáculo natural, con escasas variaciones, distingue al discurso literario argentino frente al centenario. En un determinado nivel, este discurso ha adquirido un fuerte matiz despolitizado, como consecuencia de su intención desurbanizadora en pos del resaltamiento de la naturaleza, el paisaje y el color local. En el paisajismo despolitizado, la mirada se posa solamente sobre el terruño, como la escenografía más propicia para el despliegue de la actividad productiva. La mirada es adánica, puesto que no se alude al conflicto social, que se destaca en la 
urbe, por medio de ideologías temerarias y extremistas traducidas en acción directa por los anarquistas. En la alusión a la naturaleza se percibe un efecto de equilibrio, sin fisuras, entre la belleza de sus formas y la trama social de los hombres que la sirven.

La referencia a la naturaleza, ya sea bajo la forma del paisaje, sus ciclos, los seres que la habitan se inscribe en la tradición horaciana que tiende una red de vínculos con el trabajo, las virtudes y las realizaciones comunitarias. Paradójicamente, la idea del progreso se reviste de tales imaginaciones rurales. Es probable que aquí se ubique otro enclave de la contradictoria modernización hispanoamericana, en razón de que el industrialismo y la urbe se asociaban, en los países metropolitanos, con la modernidad. La economía primaria resulta finalmente exaltada por los intelectuales, desde un lugar más propio de voceros del poder político. Podría decirse, entonces, que dos factores se destacan en el discurso literario del centenario: por un lado, la referencia al elemento geográfico, telúrico y, por otro; el elemento racial, como base para la definición de la argentinidad. Como es fácil deducir, la identidad es un problema esencial del momento. El factor territorial cuenta con importantes antecedentes, a saber: Mis montañas (1892) de Joaquín V.González, La guerra gaucha (1905) de Leopoldo Lugones, Recuerdos de la tierra (1896) de Martiniano Leguizamón, El país de la selva (1907) de Ricardo Rojas, Cuentos de la pampa (1903) de Manuel Ugarte. Los ejemplos se continúan con los Cuentos americanos (1904) de Rufino Blanco Fombona, la novela indígena de Alcides Arguedas, Wata Wara (1904), Sub terra (1904), Sub sole (1907) de Baldomero Lillo. En general, estos textos pertenecen a la corriente criollista que por entonces cobra valor. Se está ante el desarrollo de un proceso en el que la nación comienza a ocupar el centro de atención de la institución literaria.

\section{El ensayo de Ugarte}

Veamos más en detalle el punto de fuga que implica el americanismo ugarteano. En 1910 Ugarte produce varios hechos significativos: publica un ensayo que tuvo una gran acogida, El porvenir de América Latina; comienza su larga campaña en favor de la unidad continental y para el 25 de mayo de 1910, pronuncia, en Barcelona, una conferencia titulada "Causas y consecuencias de la Revolución Americana". Su intervención 
en este tema deja entrever una tesis histórica revisionista en lo que concierne a los motivos de la revolución y el planteo de la existencia de naciones que tienen el mismo rango que el proletariado, entre las que se cuentan las latinoamericanas. Asimismo, propone al nacionalismo como el paso previo al internacionalismo sin fronteras. Y remata su exposición diciendo "si sabemos ser modernos, el porvenir nos pertenece", en una clara apelación a descubrir una vía alternativa de modernización latinoamericana ${ }^{14}$. El problema del americanismo literario ha estado atravesado por dos vectores esenciales que lo han acompañado de manera permanente, ellos son: la autonomía intelectual y la originalidad. Ambos conceptos integran la historia literaria misma, en la medida en que al igual que un hilo atraviesa de punta a punta el sistema histórico-literario hispanoamericano $^{15}$. El americanismo literario en el que se inscribe la obra ugarteana ha diseñado una categoría en la que se implica la existencia de una gran nación americana y, por lo tanto, no ha sido nunca un programa estrictamente artístico. Como afirmación ética, el americanismo destaca la existencia de una vida y estilo propios, procurando de tal modo "llamar la atención sobre su presencia ubicada en zonas marginales de la cultura occidental" ${ }^{16}$. La originalidad favorecida no posee el sentido de la novedad que trajeron las vanguardias europeas, sino la de origen, es decir, hay originalidad no tanto porque la forma expresiva la actualice mediante cambios y rupturas, sino porque en el origen mismo latinoamericano está la marca de la singularidad. La autonomía, que no es sino un propósito descolonizador, comprende dos dimensiones complementarias: por un lado, la independencia política de cualquier tutela imperial, por otro- sin el cual es impensable la anterior-, la configuración de un arte y pensamiento propios. "Lo que hemos hecho hasta ahora-escribe Ugarte- no ha sido en resumen más que arte colonial-colonial de Francia, colonial de España, colonial de Italia-, pero arte de reflejo, belleza que no tiene ninguna marca local, ni en los asuntos, ni en la inspiración ni en la forma"17.

La circunstancia en que se plantea la autonomía debe verse como un punto de inflexión en el que operan, a un mismo tiempo, un balance crítico de época y una apertura hacia una perspectiva cultural nueva. Además de su frecuencia, estos planteos autonomistas poseen el carácter de fundacionales: Andrés Bello enancado entre el clasicismo y el romanticismo propugnó la independencia intelectual americana, José Martí lo esboza en "Nuestra América", Rubén Darío lo intentó en la 
renovación poética. En el caso de Ugarte, la pretensión de un arte original se correlaciona con la determinación de la especificidad del hombre hispanoamericano.

Después de un siglo-escribe Ugarte- de independencia, cuando el Continente empieza a tomar un color inconfundible, cuando el carácter nacional surge en todas las manifestaciones y cuando la personalidad naciente irradia hasta el punto de envolver en su tromba a los recién llegados, no es posible prolongar un arte ajeno al territorio, a los habitantes ya la bandera interior ${ }^{18}$.

El americanismo ugarteano podría definirse, entonces, como el esfuerzo por sortear la imitación de los hábitos de consumo y legitimar los principios de producción. La aspiración a una elaboración literaria original se corresponde con la idea de la autonomía política y económica, es decir, lo contrario de lo que sucedía en las relaciones económicas entre las metrópolis y las periferias neocoloniales. Los realemas de la formación discursiva del Centenario, como hemos dicho, han sido predominantemente geográficos: paisaje, costumbres, tipos característicos. Rodó había entrevisto, tempranamente, que el carácter nacional (americano) de una literatura no sólo debía buscarse en el reflejo de la peculiaridad de la naturaleza exterior, la descripción de las costumbres o la idealización de las tradiciones. ${ }^{19}$ Pictórico por su tendencia al contorno, mimético por su realismo, ingenuo por la escasa espesura, la formación discursiva del centenario se detuvo en el color local, el costumbrismo regional y la exterioridad americana, sin arrimarse a la expresión de la patética de la vida ni a la dramaticidad de conciencia. El americanismo ugarteano, en cambio, no se deriva de los contenidos temáticos, tópicos ruralistas ni paisajismo de color (principios actuantes durante el romanticismo), sus líneas maestras se enraízan en una categoría óntica, por un lado y una especialización de los sentidos, por otro. Ugarte intenta resolver el siguiente dilema: "¿el 'nacionalismo' artístico consiste en los asuntos o en la forma? Si consiste en los asuntos, Loti no sería un escritor francés; si en la forma, d'Anunnzio no podría llamarse italiano." ${ }^{20}$ En la opción naturaleza americana-cultura de occidente, se sobreimprime la polémica referente a la sinceridad y autenticidad en contraste con la concepción ideal de la obra de arte. ${ }^{21}$ "Porque literatura nacional-razona Ugarte- no debe ser para nosotros la que renueve exclusivamente los asuntos y las perspectivas locales, sino 
la que amplifica una manera propia de sentir y de ver a la vasta diversidad de la vida." ${ }^{22}$ La elevación de la sinceridad a un valor estético facilitó la superación de la imitación y la emergencia de los "primeros personales" ${ }^{23}$, que resume la búsqueda constante de la autonomía artístico- intelectual americana.

Por último, la experiencia europea no está en el reverso del americanismo, como lo fue respecto de la estética criollista en pleno mundonovismo de los años 20 , sino que se encuentra en la génesis del mismo, bajo la forma de un redescubrimiento de América. El hecho se produce por contraste entre un mundo hiperurbanizado (como París) y la realidad americana (naturaleza), pero también porque la tendencia novecentista a la que pertenece Ugarte delineó una teoría literaria que se incluía en un proyecto más amplio. El objetivo perseguido, como se ha dicho, respecto de la autonomía y la originalidad, tenía aristas político-culturales, entre las que se destacan la propuesta de integración continental, la elaboración de una noción de supranacionalidad y la ambición de difundir la cultura de América en el mundo europeo.

El retorno a la naturaleza, en tanto modelo de la ingenuidad y sencillez como línea maestra de la formación discursiva del Centenario se inserta como tópico en un campo de fuerzas políticosculturales hegemónicas. Pero este bloque, si homogéneo en la superficie, tal como la demuestra la producción discursiva que vimos, se ha agrietado, por cuyas hendiduras se filtrará otra Argentina, dando comienzo a nuevo ciclo de su historia. Dentro del sistema literario centenarista, el discurso ensayístico ugarteano oficia, al cabo, de punto de fuga, tan sólo porque las condiciones históricas hispanoamericanas no permitían otra alternativa. 


\section{Notas:}

1 "El uso literal. que convierte en insuperable el viejo acontecimiento. desemboca a fin de cuentas en el sometimiento del presente al pasado. El uso ejemplar, por el contrario, permite utilizar el pasado con vistas al presente. aprovechar las lecciones de las injusticias sufridas para luchar contra las que se producen hoy día. y separarse del yo para ir hacia el otro." Todorov, Tzvetan. Los abusos de la memoria. Barcelona. Paidos. 2000. p.32.

2 Entre las últimas incursiones en el tema se encuentra el trabajo de Graciela Montaldo. Dice esta crítica: "Los inmigrantes. en la ciudad. ayudan a dibujar la estampa de un campo argentino en la imaginación de muchos de nuestros intelectuales como lugar de origen de las diferencias, donde el enigma del presente puede desentrañarse." De pronto. el campo. Rosario, Beatriz Viterbo, 1993. p.22. Es de obligada referencia para el tema el libro de Onega, Gladys, La inmigración en la literatura argentina. Buenos Aires, Galerna, 1969. También el ensayo de David Viñas, Literatura argentina y realidad política. Buenos Aires, Jorge Alvarez Editor. 1964.

3 La celebración del Centenario posee un doble juego con la tradición; por un lado. busca fijar una tradición propia dentro de un pasado selectivo, y, por otro, el acontecimiento mismo de conmemorar forma parte de una tradición inaugurada con la modernidad. Robespierre había contribuido a la formación de una especie de religión de la patria. en la cual el estado revolucionario se rodeaba de las pompas de las ceremonias religiosas. El objetivo que se persigue por medio de la gran escenificación celebratoria es el de producir una influencia sobre la imaginación de las masas. Nótese la implicancia religiosa de las procesiones cívicas llevadas a cabo durante 1910 en la Argentina o las oraciones pronunciadas y colocación de piedras fundamentales, etc. En un ensayo reciente J. J. Sebreli ha tratado este tema: "Los jacobinos. aun los ateos, creían que las masas no podían existir sin una religión -el escepticismo o el deísmo filosófico sólo era apto para las elites dirigentes- e intentaron convertir al Estado en una nueva Iglesia. y a la política en una nueva fe fueron los creadores de las grandes religiones políticas/ .../Como toda religión, la Revolución necesitaba también un ritual, ceremonias, fiestas celebratorias." Las aventuras de la vanguardia. Buenos Aires, Sudamericana, 2000, p.196. Véase también de J. J Sebreli, El vacilar de las cosas. Buenos Aires. Sudamericana, 1994, especialmente el capítulo "Revolución. religión y fiesta".

4 Halperín Donghi. Tulio. Historia contemporánea de América Latina. Madrid, Alianza, 1981, especialmente el capítulo "Surgimiento del orden colonial".

5 Con la presidencia de Roque Sáenz Peña. iniciada en 1910, vendrá la sanción de la ley del voto secreto y con él el advenimiento de las clases medias al poder del estado. Estos cambios no significan que la estructura del orden neocolonial fuera puesta en cuestión, sino que los nuevos actores políticos "se oponen escribe Halperín-. antes que al lazo colonial de nuevo estilo que está en la base del orden latinoamericano, a la situación privilegiada que dentro de ese orden se ha reservado lo que se llama la oligarquía." Ibid.. p. 297.

6 Véase el trabajo de Carlos Altamirano y Beatriz Sarlo. "La Argentina del Centenario: campo intelectual. vida literaria y temas ideológicos". En: Ensayos argentinos. De Sarmiento a fa vanguardia. Buenos Aires. Centro Editor de América Latina. 1983. Para una visión histórica del tema: Saenz. Jimena. Entre dos centenarios. 1910-1916. Buenos Aires, Ediciones La Bastilla. 1976. .

7 La función del intelectual y el lugar de la institución literaria en la sociedad forman parte del debate de este momento. Una respuesta encontrada por los escritores consistió en retomar las 
relaciones con la política. como voceros del estado argentino. Véase Masiello. Francine. Lenguaje e ideología. Las escuelas argentinas de vanguardia. Buenos Aires, Hachette. 1986. especialmente el cap."La condición del escritor: una afirmación del yo".

Ugarte, Manuel. Escritores iberoamericanos de 1900. Santiago de Chile, Edil. Orbe. 1943.

9 Terán. asear. En busca de la ideología argentina. Buenos Aires, Catálogo Editora, 1986. p.18.

10 Se compone de cuatro 'ensayos: El porvenir de América Latina (1910). Mi campaña hispanoamericana (1922). La Patria Grande (1922), El Destino de un continente (1923).

11 Said. Edward. Imperialismo y cultura. Barcelona. Anagrama. 1996.

12 El autor del artículo "Las dos Argentinas" se propone "estudiar aquí los cimientos falsos, carcomidos. sobre los cuales reposa el viejo y tullido edificio político;'..l." Tamini. Luis. "Las dos Argentinas". En: Revista de Derecho. Historia y Letras, julio. 1909. p.327. En la misma revista. Ugarte se refiere a la existencia de dos América claramente y antagónicamente definidas. en clara respuesta a las políticas panamericanistas, Ugarte. Manuel "Los Estados Unidos y la América del Sur". En: Revista de Derecho, Historia y Letras. abril. 1910.

13 Dice Graciela Montaldo: "En las cabezas de los intelectuales argentinos estaban tanto la historia política de los indios y los gauchos como las historias forjadas en los libros y los folletos o tiras gráficas y las historias "del campo", Normalizar esos discursos. desentrañarles un sentido. ponerles el orden que en la plaza pública no tenían. va a producir un conjunto de libros fundamentales para la cultura argentina; fundamentales no sólo porque inciden en el discurso de los intelectuales sino porque explicitan una problemática a través de la cual se reinventan nuevas mitologías e interpretaciones sobre lo argentino y arrojan efectos culturales más allá de su campo Inmediato." Op.cit" p.31.

14 Ugarte, Manuel. Mi campaña hispanoamericana. Barcelona. Editorial Cervantes. 1922. p.47.

15 Dice Rama que "el obsesivo intento de lograr una autonomía se define por la constancia del autoexamen hispanoamericano en la literatura y en la crítica del continente", Rubén Daría y el modernismo. Caracas. EBUC. 1970. p. 21 Un ejemplo destacado en la crítica lo constituye Pedro Henríquez Ureña. en razón de que la utopía -la "búsqueda de nuestra expresión"- es uno de los supuestos historiográficos del crítico dominicano.

16 Morinigo. Mariano, Americanismo literario: formas antagónicas. Tucumán, Universidad Nacional de Tucumán, Facultad de Filosofía y Letras. 1967. p.I01.

17 Ugarte. Manuel. Las nuevas tendencias literarias. Valencia, Sempere. p,21-2. Las cursivas son nuestras.

18 Ibid.. p.148.

19 Rodó. José E.. Obras Completas. Editadas. con introducción, prólogos y notas por Emir Rodríguez Monegal. Madrid. Aguilar, 1967 p.788. 
21 El romanticismo había revolucionado la idea de la belleza. Octavio Paz ha escrito: "La estética barroca y la neoclásica habían trazado una división estricta entre el arte y la vida. Por más distinta que fuesen sus ideas de lo bello. ambas acentuaban el carácter ideal de la obra de arte. Al afirmar la primacía de la inspiración. pasión y la sensibilidad. el romanticismo borró las fronteras entre el arte y la vida: el poema fue una experiencia vital y la vida adquirió la intensidad de la poesía." Los hijos del limo. Barcelona. Se ix Barral. 1990. p.94-5.

22 Ugarte. M" Las nuevas tendencias, op.cit.. pAO.

23 Así denomina Ugarte a los artistas con conciencia personal de su producción. La joven literatura hispanoamericana. París. Armand Collin Editor. 1906. p.XXXIII. 